\title{
Sensitivities of Extreme Precipitation to Global Warming Are Lower over Mountains than over Oceans and Plains 0
}

\author{
XIAOMING SHI ${ }^{\mathrm{a}}$ AND DALE DURRAN \\ Department of Atmospheric Sciences, University of Washington, Seattle, Washington
}

(Manuscript received 13 August 2015, in final form 28 March 2016)

\begin{abstract}
Climate-model simulations predict an intensification of extreme precipitation in almost all areas of the world under global warming. Local variations in the magnitude of this intensification are evident in these simulations, but most previous efforts to understand the factors responsible for the changes in extreme precipitation focused on zonal averages and neglected zonal variations, leading to uncertainties in the understanding and estimation of regional responses. Here the spatial heterogeneity of the warming-induced response of midlatitude extreme precipitation is studied in climate-model simulations with idealized orography on the western margins of otherwise flat continents. It is shown that the sensitivity of extreme precipitation to warming (i.e., its fractional rate of increase in intensity with global-mean surface temperature) is $\sim 3 \% \mathrm{~K}^{-1}$ lower over the mountains than the oceans and plains. This difference in sensitivity is primarily produced by differences in the dynamics governing vertical ascent over the three regions. In these extreme events, mountain-wave dynamics control the moist ascent over the mountains, and the sensitivity of this ascent to global warming is mainly controlled by changes in upper-level dry static stability and the crossmountain winds. In contrast, midlatitude cyclone dynamics govern moist ascent over the oceans and plains. Ascending motions in intense midlatitude cyclones are sensitive to the ratio of the moist static stability in their saturated cores to the dry stability in surrounding regions. This ratio decreases in the warmer world, intensifying the maximum vertical velocities while reducing the horizontal extent of the regions of the rising air within the cyclone.
\end{abstract}

\section{Introduction}

The global mean precipitation increases due to global warming are limited to $\sim 2 \% \mathrm{~K}^{-1}$ because of energetic constraints on the atmosphere (Held and Soden 2006; Allen and Ingram 2002; Takahashi 2009); however, simulated precipitation extremes increase much faster over many regions of the world (Emori and Brown 2005; Kharin et al. 2007; O'Gorman 2012), strongly impacting natural disasters such as flooding and landslides (Pall et al. 2011; Rasmussen and Houze 2012). In the tropics, climate-model results constrained by

Supplemental information related to this paper is available at the Journals Online website: http://dx.doi.org/10.1175/JCLI-D-15-0576.s1.

${ }^{a}$ Current affiliation: Department of Civil and Environmental Engineering, University of California, Berkeley, Berkeley, California.

Corresponding author address: Xiaoming Shi, Department of Civil and Environmental Engineering, University of California, Berkeley, 207 O’Brien Hall, Berkeley, CA 94720.

E-mail: shixm@berkeley.edu observations suggest extreme precipitation (99.9th percentile of daily precipitation) increases at $\sim 10 \%$ per degree warming of the global mean surface temperature (O'Gorman 2012). In the extratropics, simulations suggest extreme precipitation will increase at roughly the "thermodynamic" rate of $\sim 6 \% \mathrm{~K}^{-1}$, which is the rate that would be produced by temperature increases at fixed relative humidity when vertical motions stay constant (O'Gorman and Schneider 2009a).

However, the preceding large-scale sensitivities are not necessarily representative of the regional changes that may occur in extreme precipitation over local areas because of the influence of finescale processes, such as orographic and snow albedo effects, on climate change (Diffenbaugh et al. 2005). Recent studies based on regional climate simulations suggest that in some midlatitude regions, such as the Netherlands and the western United States, extreme precipitation could increase at rates of $9 \% \mathrm{~K}^{-1}$ or higher (Dominguez et al. 2012; Attema et al. 2014).

Previously, general circulation models (GCMs) configured with intermediate complexity have been applied 
to a lot of areas, including studies of precipitation (e.g., O'Gorman and Schneider 2009b; Maroon et al. 2015), cloud processes (Medeiros et al. 2008; Voigt and Shaw 2015), the midlatitude storm track (Brayshaw et al. 2009, 2011), and the Madden-Julian oscillation (Hsu et al. 2014). The intermediate complexity in such idealized simulations help us gain a deeper understanding of the underlying physics (Held 2005), which are essential for reducing the uncertainty in estimates of the climate sensitivity and guiding adaptation to climate change at the regional level (Stevens and Bony 2013). Here we use a GCM with idealized orography to explore the fundamental physical factors producing systematic variations in extreme precipitation over midlatitude mountains, oceans, and plains. In our simulations, the earth is covered with mixed layer oceans and idealized continents with north-south mountain barriers in the northern midlatitudes. The same setting was previously used to study the response of extreme precipitation over western and eastern slopes of mountains, and it was found that the dynamics of mountain waves govern the warming-induced response of vertical motions over mountain slopes, making the sensitivity of extreme precipitation to warming different over the western and eastern slopes (Shi and Durran 2015). That previous study did not, however, consider extreme precipitation events over the ocean or the plains.

Because extreme precipitation over the plains and oceans is not constrained by mountain-wave dynamics, its sensitivity to global warming could potentially differ from that of extreme orographic precipitation. In this study we analyze large numbers of extreme events, as defined by thresholds similar to those used in previous studies (O'Gorman and Schneider 2009a; O'Gorman 2012), and compare the behavior of the precipitation extremes over mountains, plains, and oceans in current and doubled- $\mathrm{CO}_{2}$ scenarios. As explained below, the extreme precipitation over the midlatitude oceans and plains is governed by the dynamics of midlatitude cyclones, and its sensitivity to global warming is higher than the sensitivity of the extreme precipitation over the mountains by $\sim 3 \% \mathrm{~K}^{-1}$.

\section{Model and methods}

\section{a. Climate simulations}

To assess the potentially different response of extreme precipitation over midlatitude mountains, oceans, and plains, we analyzed 10 years of data for a pair of climate simulations with reference $(330 \mathrm{ppm})$ and doubled $(660 \mathrm{ppm}) \mathrm{CO}_{2}$ concentrations. The simulations are identical to those conducted in Shi and Durran (2015) with the Geophysical Fluid Dynamics Laboratory (GFDL) global High Resolution Atmospheric Model (HiRAM; Zhao et al. 2009), which were run at $\sim 50-\mathrm{km}$ horizontal resolution with 32 vertical levels. In total, 20 -yr simulations were conducted with the control and doubled- $\mathrm{CO}_{2}$ concentrations. The first 10 years were discarded as spin up because of the significant adjusting trends in them (measured by global mean surface temperature), and 6-hourly data from the last 10 years were retained for analysis. The global-mean surface temperature increase due to doubling $\mathrm{CO}_{2}$ was $5 \mathrm{~K}$.

We used idealized topography in these simulations, with four north-south mountain barriers at the western margin of otherwise flat continents extending $30^{\circ}$ eastwest in longitude and symmetrically distributed about the pole in the latitude band between $30^{\circ}$ and $60^{\circ} \mathrm{N}$; the remainder of the planet (i.e., all grid points other than mountains and plains) is covered with a 24-m-deep mixed layer ocean. The idealized orography and landsea distribution is illustrated in Fig. 1. This symmetric configuration allows us to obtain a larger sample size by aggregating the events over all four mountains, continents, and midlatitude ocean basins.

The mountains, defined by Eqs. (1) and (2) in Shi and Durran (2015) are $2.5 \mathrm{~km}$ high and $480 \mathrm{~km}$ wide. Temperature evolution of the mixed layer ocean follows the heat budget Eq. (1) in Frierson et al. (2006). Surface processes on the idealized continents are simulated with HiRAM's land surface model, version 2 (LM2). The vegetation in LM2 is set to "broadleaf/needleleaf trees" on the western slopes of the mountains and to "grasslands" on the eastern slopes and plains. The annual cycle was included using daily averaged insolation. Other standard physical schemes described in Zhao et al. (2009), such as cumulus and boundary layer parameterizations, are also used in our simulations.

\section{b. Identification of extreme precipitation events}

The idealized mountains are well resolved by the global model and their simple geometry facilitates the comparison of extreme events across different latitudes. The original data on cubed-sphere grids of HiRAM were interpolated onto a $0.5^{\circ}$ latitude by $0.625^{\circ}$ longitude grid first, then we divide the midlatitudes into $2.5^{\circ}$ wide bands, in order to obtain larger sample sizes for subsequent analysis. Within each band, 6-hourly precipitation is accumulated at each grid cell at all longitudes and all times during the final 10 years of the simulation and collected for each of three surface types: oceans, plains, or mountains. The precipitation accumulated over each 6-h period of the 10 years at each grid point is flagged as extreme if it exceeds the 99.9th percentile value in its respective dataset. Over oceans and 


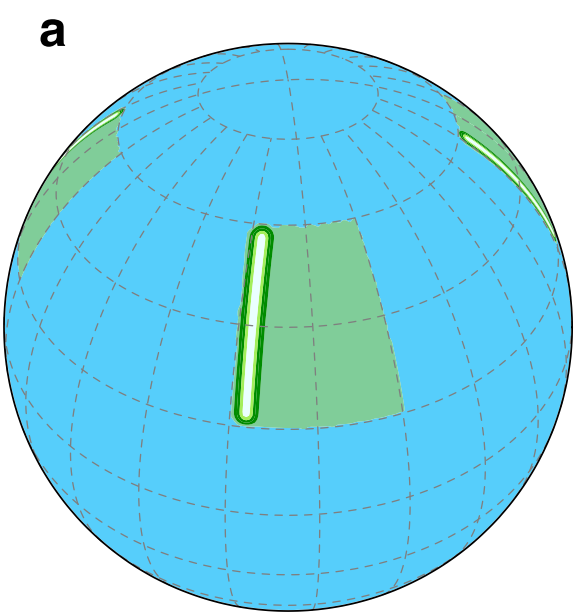

b

FIG. 1. Shape of the idealized mountains and continents. (a) Distribution of the mountains (white), continents (green), oceans (blue). (b) Topographic contours (at elevations of 0,1 , and $2 \mathrm{~km}$ ) for the mountains located at the western edge of each continent.

plains, most of the extremes are in summer and autumn, possibly due to the dependence of saturation vapor pressure on temperature. Over mountains, most of the extremes occur over the wetter western slopes in autumn and winter. This difference in seasonality arises from the well-established dependence of heavy orographic precipitation on strong cross-mountain winds (Ralph et al. 2006).

The above approach of selecting extreme precipitation events treats each 6-h period at each grid cell as a single event, and extremes are defined as the top $0.1 \%$ of all precipitation events in the 10 years over a given type of surface. This threshold for extreme precipitation is similar to that used in O'Gorman and Schneider (2009a) to study zonally averaged changes in extreme precipitation. In each $2.5^{\circ}$ latitude band between $32.5^{\circ}$ and $57.5^{\circ} \mathrm{N}$, there were roughly $27000 \mathrm{ex}-$ treme events over the oceans, 11000 over the plains, and 4000 over the mountains. The numbers of events over mountains, oceans, and plains are different because of the different areas of these regions in the idealized simulation. With such large samples, our analyses described in other sections are expected to be statistically robust. The bands $30^{\circ}-32.5^{\circ}$ and $57.5^{\circ}-60^{\circ} \mathrm{N}$, which contain the ends of the mountains, were neglected because the lateral diversion of air around the end of the mountain can introduce different dynamical regimes. The relatively short 6-h time interval allows us to numerically evaluate various terms contributing to the precipitation and compare them with the instantaneous atmospheric fields archived at the middle time of each interval.

\section{c. Linear mountain wave model}

In section $4 \mathrm{a}$, the linear mountain wave model developed by Klemp and Lilly (1975) will be used to evaluate the importance of large-scale environment variables (e.g., mean upper-troposphere static stability) in the extreme precipitation events over mountains. This same model was previously applied to a much smaller set of extreme events in (Shi and Durran 2015). The mountain-wave model solves the linear, hydrostatic, steady-state Boussinesq equation for vertical velocity. The atmosphere is assumed to comprise three layers with constant static stabilities and constant wind shears in each layer. In our case, the three layers are the moist nearly neutral lower half of the troposphere, the dry stable upper half of the troposphere, and the stratosphere. Vertical velocities in the linear model are predicted by Eqs. (2) and (6) in Klemp and Lilly (1975), which give expressions for Fourier components of vertical velocity. We evaluate them at $z=1.75 \mathrm{~km}$ above the surface of the linear model; that surface is assumed to be at $1.25 \mathrm{~km}(1 / 2$ the total mountain height $h_{m}$ ), so that the effective level at which $w$ is evaluated is $3 \mathrm{~km}$, where orographic ascents tend to be strongest. The mean zonal wind speed just above boundary layer top, $\sim 800 \mathrm{hPa}$, is computed with HiRAM simulation data, and used as the wind speed $(U)$ at the bottom of the linear model. The same representative value $\alpha=4 \times 10^{-3} \mathrm{~s}^{-1}$ is used for the vertical wind shear in the lowest two layers of the linear model, for both the control and warmed climate. The static stability in the stratosphere is set as a value representative of both the control and warmed climates, $N_{3}=2 \times 10^{-2} \mathrm{~s}^{-1}$ (the subscript 3 refers to the top layer in this three-layer model). The boundary between the lowest layer and the middle layer of the linear model is assumed to be at onehalf the tropopause height $(H)$. Although in some events the middle-layer air can become saturated, the small amount of moisture in the upper troposphere makes the moist static stability in that layer similar to the dry stability. Therefore, we used the mean dry stability between 300 and $500 \mathrm{hPa}$ from HiRAM simulation data for the stability of the middle layer $\left(N_{2}\right)$ in the linear model. The mean moist static stability between 500 and $850 \mathrm{hPa}$ from the HiRAM data was used for the stability in the lowest layer $\left(N_{1}\right)$.

The parameters, $N_{2}, U$, and $H$, were evaluated from simulation data upstream for each event, $\sim 100 \mathrm{~km}$ to the west of mountains; $N_{1}$, which must be calculated in a saturated environment, was evaluated above mountains slopes in the columns producing extreme precipitation. The values of these parameters were averaged over the roughly 4000 extreme orographic 
TABLE 1. Parameters of the linear mountain wave model. Here $i=1$ indicates the bottom layer, and $i=3$ indicates the top layer. Vertical wind shear is assumed to vanish in the top layer. Moist Brunt-Väisälä frequency is used for the saturated bottom layer, and dry Brunt-Väisälä frequency are used for others. Specific parameter values used in section $4 \mathrm{a}$ are provided in the supplementary material.

\begin{tabular}{ll}
\hline \hline$U$ & Bottom-level wind speed \\
$\alpha_{i}(i=1,2)$ & Vertical wind shear \\
$N_{i}(i=1,2,3)$ & Brunt-Väisälä frequency (static stability) \\
$H$ & Tropopause height \\
$h_{m}$ & Mountain peak elevation \\
\hline
\end{tabular}

precipitation events in each latitude band to determine the mean environments for both the control and doubled- $\mathrm{CO}_{2}$ climates. Table 1 summarizes parameters in the linear model, and specific parameter values used in section $4 \mathrm{a}$ are provided in supplemental Table S1.

\section{Responses of precipitation extremes}

\section{a. Precipitation and condensation sensitivities}

Figure 2a compares the sensitivities of extreme precipitation, defined as the percentage change in mean intensity divided by the global-mean surface temperature increase, over the mountains, oceans, and plains in each latitude band. The sensitivity of extreme precipitation over the oceans is similar to that over the plains, about $8 \% \mathrm{~K}^{-1}$. In contrast, the sensitivity of extreme precipitation over the mountains is lower, just $5 \% \mathrm{~K}^{-1}$. The average overall sensitivity of midlatitude extreme events in our HiRAM simulations, computed without differentiating between the regions, is about $7 \% \mathrm{~K}^{-1}$, which is similar to previous estimates of midlatitude sensitivities from the phase 3 of the Coupled Model Intercomparison Project (CMIP3) archive O'Gorman and Schneider 2009a). Though not shown here, the sensitivity of extreme precipitation over the Southern Hemisphere midlatitude oceans is consistent with its Northern Hemisphere counterpart. As apparent in Fig. 2a, the dependence of all of these sensitivities on latitude is relatively weak, although there is an average south-north increase of about $1 \% \mathrm{~K}^{-1}$ over both the mountains and the plains.

The sensitivity of the extreme precipitation at each surface grid point is well approximated by the sensitivity of the vertically integrated condensation rate $C$ above that point, as shown in Fig. 2b. Defining precipitation efficiency $\mathrm{PE}$ as the ratio of surface precipitation $P$ to the vertical integral of condensation aloft (i.e., $\mathrm{PE}=P / C)$, the sensitivity of PE can be estimated as the

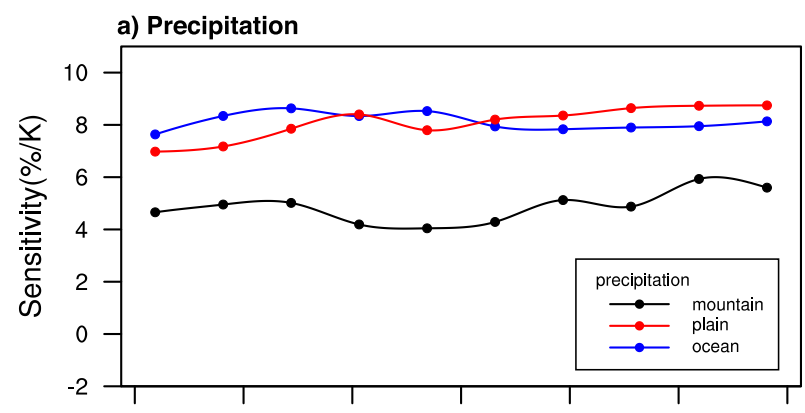

b) Condensation \& precipitation efficiency

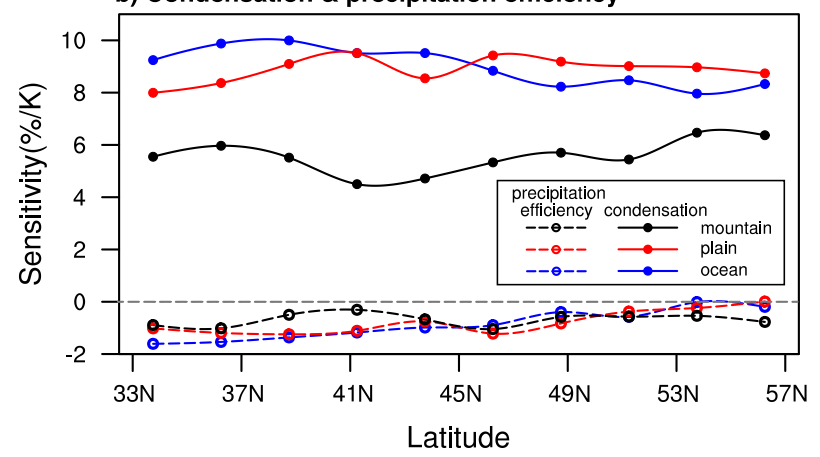

FIG. 2. Sensitivity of (a) precipitation rate, (b) vertically integrated condensation rate, and precipitation efficiency of extreme events plotted for each latitude band (solid dots) over the mountains, oceans, and plains. The sensitivity is defined as the percentage change in mean intensity divided by the global-mean surface temperature increase.

difference between the sensitivity of precipitation and condensation, because $\delta \mathrm{PE} / \mathrm{PE} \approx \delta P / P-\delta C / C$, where $\delta$ denotes the change in the extreme-event averages between the doubled- $\mathrm{CO}_{2}$ and control climates. As shown in Fig. 2b, the changes in precipitation efficiency are small, and therefore not critical for the difference between the response of extreme precipitation over mountains and that over plains and oceans.

The above sensitivities are primarily due to changes in the grid-resolved fields, since over $98 \%$ of the precipitation in the extreme events in Fig. 2 is generated by grid-resolved process, rather than parameterized convection. Parameterized convection does produce $40 \%-$ $50 \%$ of the total July precipitation along the southern margins of the continents and is more active farther south over the tropical oceans, but typical static stabilities during the extreme midlatitude events are approximately neutral to moist adiabatic ascent (rather than convectively unstable), as was observed, for example, during the extreme Colorado flooding of September 2013 (Shi and Durran 2015; Gochis et al. 2015). This fact allows us to obtain a deeper understanding of the changes in precipitation extremes by analyzing the resolved grid-scale variables of the climate model, which is described in the next section. 


\section{b. Thermodynamic and dynamic sensitivities}

The condensation rate in a saturated grid cell may be estimated by assuming adiabatic lifting maintains the water vapor content of the rising air at saturation; the condensation in each cell can be summed through the vertical column to estimate $C$, the vertically integrated condensation rate. The change in precipitation $\delta P$ can then be estimated from two contributions. One contribution is from the dynamics and arises from changes in the vertical velocities $\delta w$. The second contribution is from thermodynamics and arises from changes in the adiabatic lapse rate of the saturation specific humidity of water vapor $\delta \gamma^{*}$. The total change in precipitation may be partitioned between these contributions as follows.

Let $w$ be the vertical velocity, and $\gamma^{*}=-d q_{s} / d z$ be the adiabatic lapse rate of the saturation specific humidity of water vapor $q_{s}$. The latter can be expressed analytically as a function of temperature and pressure, as given by Eq. (6) in Shi and Durran (2014). Neglecting precipitation efficiency, which will factor out of our final expression if we ignore its small variations (Fig. 2b), the precipitation at the surface equals the columnintegrated condensation aloft $C=\sum_{k} s_{k} w_{k} \gamma_{k}^{*}$, where $k$ indexes the vertical level and $s_{k}=\Delta p_{k} / g$ in saturated grid cells, but is zero otherwise. Here $\Delta p_{k}$ is the pressure thickness of layer $k$ and $g$ is the gravitational constant. Denoting the averaging over extreme events in one latitude band under the control and warmer climates by $\overline{()}^{c}$ and $\overline{()}^{w}$, respectively, the change in the extremeevent-averaged column-integrated condensation is

$$
\delta C=\bar{C}^{w}-\bar{C}^{c}=\sum_{k} \overline{\left(s_{k} w_{k} \gamma_{k}^{*}\right)^{w}}-\sum_{k} \overline{\left(s_{k} w_{k} \gamma_{k}^{*}\right)^{c}} .
$$

The preceding is approximated as

$$
\delta C \approx \sum_{k} \overline{\overline{\left(s_{k} w_{k}\right)}} \delta \gamma_{k}^{*}+\sum_{k} \overline{\overline{\left(s_{k} \gamma_{k}^{*}\right)}} \delta w_{k},
$$

where the double overbar denotes the average over extreme events in both climates. The two terms on the right-hand side are the thermodynamic and dynamic response, respectively. Instantaneous values of the fields at the middle of each 6-h precipitation period were used to evaluate these expressions.

Figure 3 compares the thermodynamic and dynamic sensitivity of extreme precipitation over the mountains, oceans, and plains in each latitude band. Thermodynamic sensitivities are similar (around $6 \% \mathrm{~K}^{-1}$ ) in all latitude bands with less than a $1 \% \mathrm{~K}^{-1}$ variation between them. In contrast, there is a large difference in the dynamic sensitivities between the mountains and the flat areas in all

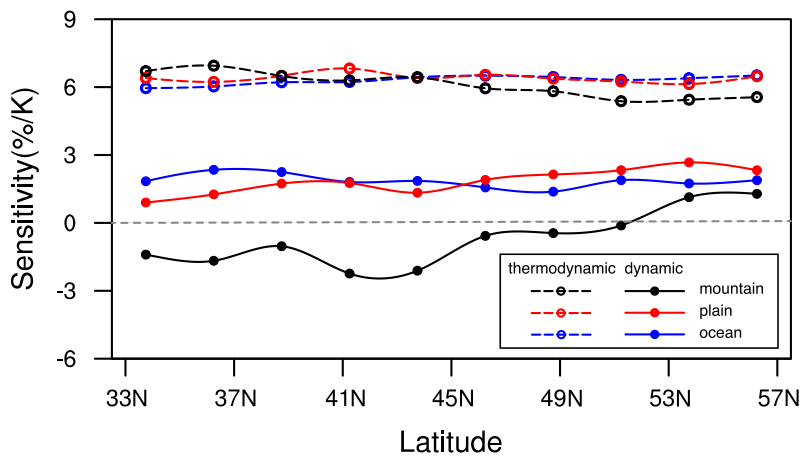

FIG. 3. Sensitivity of dynamic and thermodynamic response of extreme precipitation events plotted for each latitude band (solid and dashed lines) over the mountains, oceans, and plains.

except the two northernmost latitude bands. The dynamic sensitivities over mountains are near zero or negative in most bands, while over the oceans and plains, the dynamic sensitivities are positive, with values between $1 \%$ and $2 \%$ $\mathrm{K}^{-1}$. Except in the northernmost two bands, the differences between the dynamic sensitivities over flat areas and mountains explain most of the differences in the sensitivities of extreme precipitation over those regions.

It is not surprising that thermodynamic sensitivities are very similar over mountains, plains, and oceans, because $\gamma^{*}$ is only a function of temperature and pressure. Figure 4 shows vertical profiles ${ }^{1}$ of $\gamma^{*}$ during the extreme events over each region in the reference climate and its change due to warming, $\delta \gamma^{*}$. The values of $\gamma^{*}$ decrease quickly with altitude over each region because the saturation vapor pressure decreases as the temperature drops with altitude. Yet the maximum of $\delta \gamma^{*}$ is not near the surface, but rather in the middle troposphere. This is because the sensitivity of $\gamma^{*}$ to warming (in \% $\mathrm{K}^{-1}$ ) is larger at cold temperatures (Shi and Durran 2014). Both $\gamma^{*}$ and $\delta \gamma^{*}$ exhibit only minimal differences between the mountains, oceans, and plains because, at a given latitude, there is only a slight difference in the environmental temperatures above these regions.

The differences in dynamic sensitivities for the extreme precipitation events shown in Fig. 3 suggests there are significant differences in the global-warming-induced changes in the vertical velocities over the mountains, oceans, and plains. Figure 5 compares vertical profiles of $w$ during the extreme events over each region in the reference climate. Over the oceans and the plains, a deep region of ascent extends from the surface to at least $200 \mathrm{hPa}$, and the peak ascent near $500 \mathrm{hPa}$ is stronger and

\footnotetext{
${ }^{1}$ In Figs. 4 and 5, the vertical profiles over the mountains are scaled to begin at the height of middle of the mountain slope before computing their average.
} 

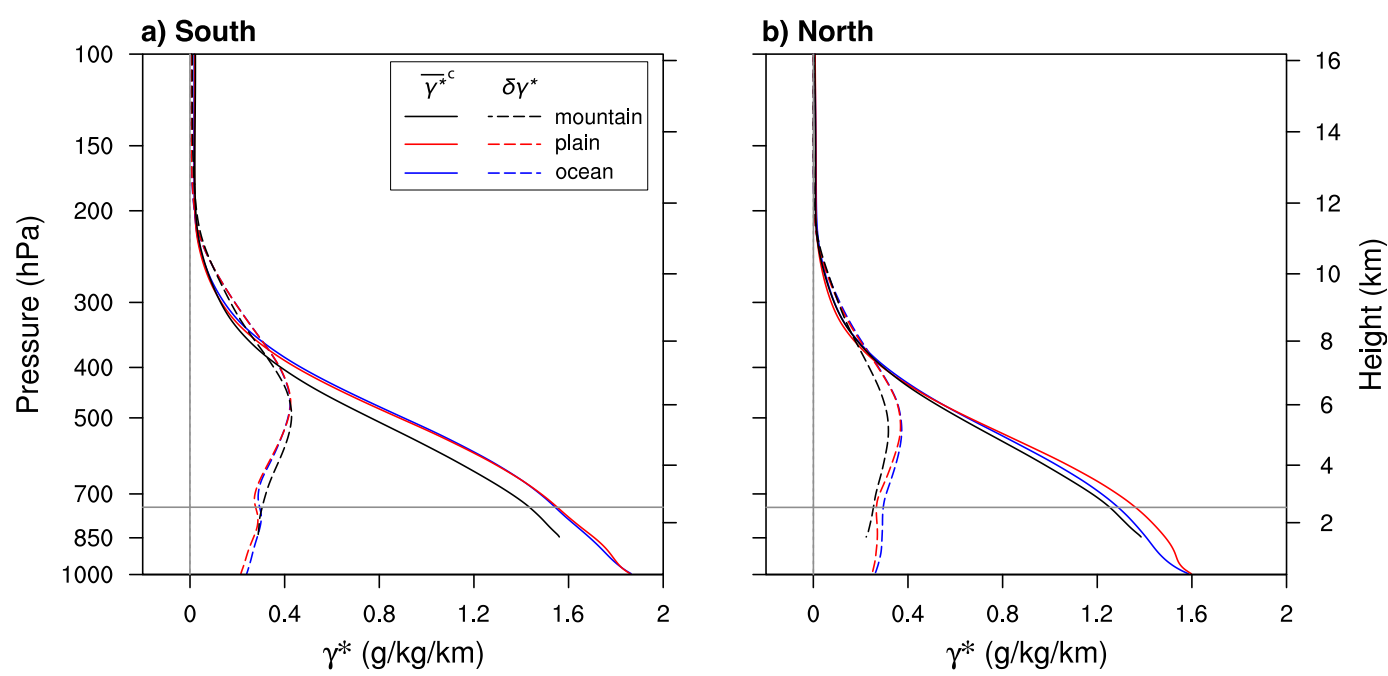

FIG. 4. Mean profiles of the moist adiabatic lapse rate of saturated specific humidity in extreme precipitation events from the control simulation $\left(\overline{\gamma^{* c}}\right)$ and their changes due to warming $\left(\delta \gamma^{*}\right)$. Profiles are averaged over the five (a) southern $\left(32.5^{\circ}-45^{\circ} \mathrm{N}\right)$ and $(\mathrm{b})$ northern $\left(45^{\circ}-57.5^{\circ} \mathrm{N}\right)$ latitude bands. The horizontal gray lines indicate the peak elevation of the mountains $(2.5 \mathrm{~km})$.

at a higher altitude in the southern half of the analysis region (Fig. 5a) than in the north (Fig. 5b). In contrast, the vertical velocity over the mountains, which is similar in the south and north, peaks at much lower levels (near $700 \mathrm{hPa}$ ), and becomes strongly negative above $250 \mathrm{hPa}$.

Also shown in Fig. 5 are profiles of $\delta w$, the changes in $w$ due to warming. In the north (Fig. 5b) all three $\delta w$ profiles are weakly negative below $700 \mathrm{hPa}$ and become positive farther aloft where $\delta w$ is largest for the oceans and smallest for the mountains. The relative strengths of these positive $\delta w$ account for the average differences in the dynamic sensitivity over the five northern latitude bands in Fig. 3. The changes in $\delta w$ in the south also account for the dynamic sensitivities in the southern latitude bands, but the character of those changes is different. In the south (Fig. 5a), the $\delta w$ over the mountains is strongly negative between mountain-top height and about $550 \mathrm{hPa}$, and its extreme is roughly 4 times more negative than that for the weak low-level negatives that occur for $\delta w$ over the oceans and the plains. Since the moisture content of the atmosphere decreases rapidly with height, the dynamic sensitivity is most strongly affected by changes in the ascent at low levels, where the negative values of $\delta w$ are responsible for the negative sensitivities of orographic precipitation apparent in the southern latitude bands in Fig. 3.

\section{Changes in the vertical velocity}

\section{a. Over the mountains}

Recent studies using the linear mountain-wave model described in section $2 \mathrm{c}$ demonstrate that gravity waves play a key role in regulating the intensity of orographic precipitation under stable or low-level moist neutral conditions (Siler and Durran 2015; Shi and Durran 2015). Here the same three-layer model is used to determine the factors responsible for the changes in the vertical velocities that give rise to the dynamic sensitivities shown in Fig. 3. Vertical velocities in each latitude band were computed from the linear model using extreme-event means of the cross-mountain wind speed $U+\alpha z$ ( $\alpha$ is the constant vertical wind shear), tropopause height $H$, and the static stabilities in the saturated lower half of the troposphere $N_{1}$, the dry upper half of the troposphere $N_{2}$, and the stratosphere $N_{3}$. The vertical velocities from this model were evaluated for a location above the middle of the windward slope at an elevation $3 \mathrm{~km}$ above mean sea level, which approximates the level where $w$ over the mountains achieves its maxima in Fig. 5.

The sensitivities $\delta w / w$ obtained with the linear model are compared to those for the vertical velocity at the same elevation from the HiRAM simulations in Fig. 6a. Although it uses linearized dynamics and a simplified environment averaged across all the extreme events in a given latitude band, the three-layer model provides reasonable approximations to the vertical-velocity sensitivities obtained directly from the full climate simulation, both of which vary between $-6 \% \mathrm{~K}^{-1}$ in the south to about $1 \% \mathrm{~K}^{-1}$ in the north. Based on its agreement with the sensitivity of the vertical velocities computed by the climate model, the linear mountainwave model may be used to estimate the contributions to $\delta w / w$ from each individual environmental parameter by holding all other parameters at their mean values 
a) South

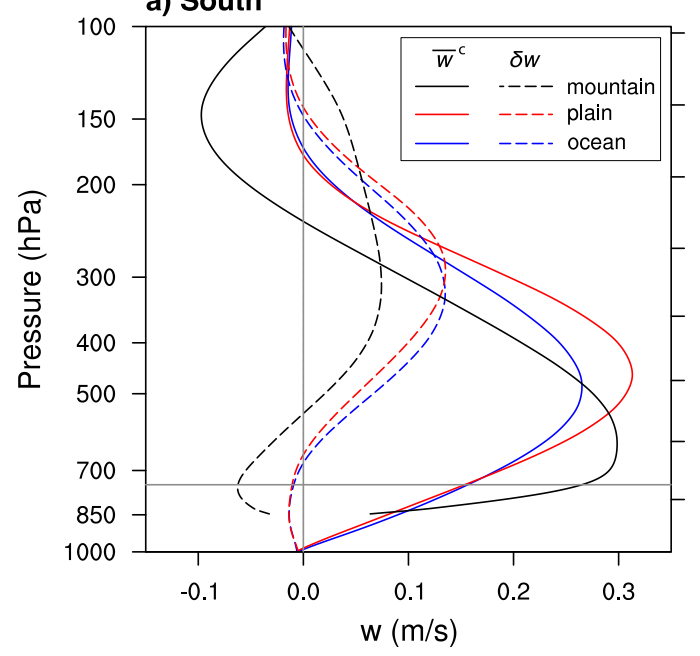

b) North

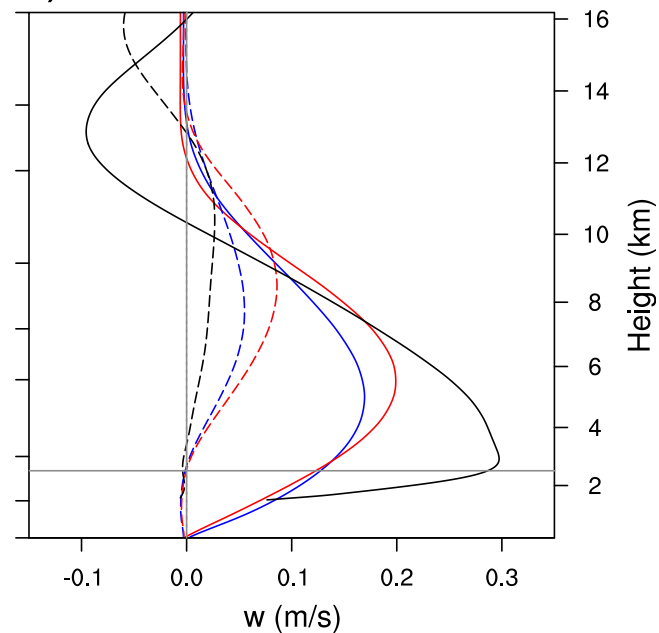

FIG. 5. Mean vertical velocity profiles in extreme precipitation events from the control simulation $\left(\bar{w}^{c}\right)$ and their changes due to warming $(\delta w)$. Profiles are averaged over the five (a) southern $\left(32.5^{\circ}-45^{\circ} \mathrm{N}\right)$ and $(\mathrm{b})$ northern $\left(45^{\circ}-\right.$ $\left.57.5^{\circ} \mathrm{N}\right)$ latitude bands. The horizontal gray lines indicate the peak elevation of the mountains $(2.5 \mathrm{~km})$.

and evaluating the $\delta w$ generated by changes in that parameter.

The sensitivities of $w$ to the most important mountainwave parameters are shown in Fig. 6b. The changes in wind speed $U$ and upper tropospheric dry static stability $\mathrm{N}_{2}$ exert the most influence on the response of windward-slope ascent during extreme orographic precipitation. Decreases in zonal wind speed in the southern latitudes weaken the ascending motions there by roughly $-4 \% \mathrm{~K}^{-1}$, while increases in the winds in the north produce a modest strengthening of $2 \% \mathrm{~K}^{-1}$. These changes in the zonal winds are consistent with a poleward shift of the jet stream similar to that found in previous studies (Vallis et al. 2015). The dry static stability increases under global warming, producing an increase in $N_{2}$ that weakens the orographic ascent at all latitudes. This dry stabilization of the atmosphere is a robust change in atmospheric structure that is not limited to just the extreme events (Vallis et al. 2015).

As also evident in Fig. 6b, the changes in the other mountain-wave-model parameters have only a minimal influence on the vertical velocities. The low-level moist static stability $N_{1}$ does not cause much change under warming. The tropopause height rises about $1 \mathrm{~km}$ in the northern latitude bands, but does not significantly modify the vertical velocity. Nevertheless, care must be taken if one wishes to generalize the influence exerted by the individual parameters shown in Fig. $6 b$ to other flow regimes; for example, changes in $H$ can be more important when $U$ is smaller, as may be the case during extreme orographic precipitation events on the eastern side of the mountain barriers (Shi and Durran 2015).

\section{b. Over the oceans and plains}

What drives the changes in vertical velocities producing extreme precipitation over the oceans and the plains? Most of these events occur just to the northwest of the low pressure center in midlatitude cyclones. As shown by the composites of surface pressure and lowlevel temperatures for oceanic extreme events in the control climate plotted in Fig. 7, the heaviest precipitation develops in a region of strong horizontal temperature gradients where heavy rainfall associated with warm or occluded fronts is observed in marine cyclones (Chang et al. 1993).

Figure 8 compares the 500 -hPa vertical velocities in the extreme events over oceans in the control and warmer climates, composited over the same two latitude bands used in Fig. 7. The ascending motions in the center of the composite storms are stronger in the warmer climate, consistent with Fig. 5. Moreover, as the centers of rising motion intensify, they contract to a smaller horizontal area; this is more obvious in the south, where the areas enclosed by the 3 and $7 \mathrm{~cm} \mathrm{~s}^{-1}$ contours are clearly smaller in Fig. 8c than in Fig. 8a. An alternate way to assess the change in updraft area is to compute $A_{s}$, the fraction of the grid cells in which condensation is occurring at $500 \mathrm{hPa}$ (owing to grid-scale ascent) in a $50^{\circ}$ latitude by $70^{\circ}$ longitude box centered on the point with the maximum extreme precipitation in each composite. Consistent with Fig. $8, A_{s}$ (Table 2) decreases in the warmer climate, and the relative decrease is largest in the south. Thus, there is a systematic change in the structure of the cyclones in response to the warming: the updrafts in the center of the 


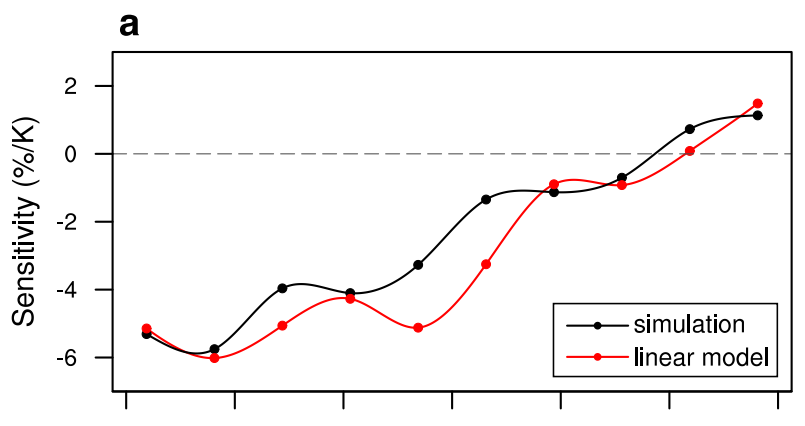

b

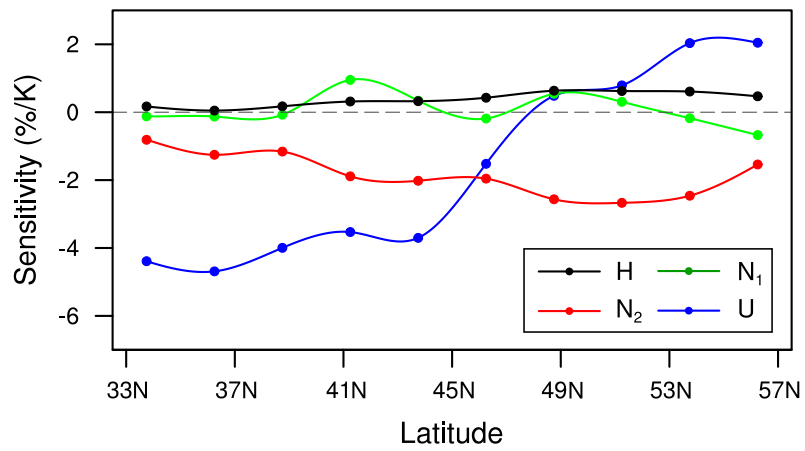

FIG. 6. Sensitivities in the vertical velocities over mountains to surface global warming. (a) Comparison of vertical velocity sensitivities from the linear model and HiRAM simulation at the 3-km level. (b) The contributions to $\delta w / w$ in the linear model from tropopause height $(H)$, moist static stability of the lower half of the troposphere $\left(N_{1}\right)$, dry static stability of the upper half of the troposphere $\left(N_{2}\right)$, and bottom level wind speed $(U)$. Negative values imply reductions in ascent due to warming.

storms become stronger, while also contracting into a smaller horizontal area. Similar reduction of the scale and intensification of the precipitation occurring near the center of extratropical cyclones have recently been obtained in idealized simulations of warmer (Pfahl et al. 2015) or artificially moistened (Booth et al. 2013) climates.

This area contraction and intensification of the ascending regions in extratropical cyclones in the warmer climate is likely produced by the basic dynamics of moist baroclinic instability. Emanuel et al. (1987) showed that when the effective potential vorticity (PV) becomes small, the region of ascent intensifies and collapses in horizontal scale. The asymmetry between the ascending and descending regions of the cyclone are driven by the differences in PV in each region, which are in turn linked to the difference between the moist and dry static stability. Also shown in Table 2 are the square of the moist ${ }^{2}$ and dry static stabilities $\left(N_{m}\right.$ and $\left.N\right)$ in the saturated and dry regions of a $50^{\circ}$ latitude by $70^{\circ}$ longitude box centered on the

\footnotetext{
${ }^{2}$ The moist Brunt-Väisälä frequency is computed using Eq. (5) in Kirshbaum and Durran (2004).
}

point with the maximum extreme precipitation in the composite cyclones shown in Fig. 8. As the climate warms, $N_{m}^{2}$ decreases while $N^{2}$ increases in both latitude bands. The values of $N_{m}^{2}$ appearing in Table 2 are not exceptionally low, in part because they are computed at $500 \mathrm{hPa}$ where the decrease in water vapor with height shifts the values of the moist stability toward the dry static stability, and in part because they are averages that include all of the saturated regions surrounding the cyclone, not just the most intense updrafts. ${ }^{3}$ Nevertheless, the differences in the effective static stabilities between the moist and dry regions, and between the control and warmer climate, are pronounced and likely contribute to the intensification and contracted cores of the updrafts in the cyclones in the doubled- $\mathrm{CO}_{2}$ climate via the processes identified in Emanuel et al. (1987).

\section{c. Diabatic and adiabatic heating}

As the climate warms, the reduction in moist static stability in the ascending branches of these cyclones is produced by increases in latent heating despite an accompanying increase in the dry static stability. To better appreciate the contributions of these two factors to the moist dynamics, we evaluate their sensitivity to surface warming during extreme precipitation events over the oceans and the plains. The thermodynamic equation can be expressed in terms of the potential temperature $\theta$ as

$$
\frac{\partial \theta}{\partial t}+\mathbf{V} \cdot \nabla \theta+w \frac{\partial \theta}{\partial z}=F_{\theta},
$$

where $\mathbf{V}$ is the horizontal wind vector, and $F_{\theta}$ is the sum of diabatic forcing due to latent heating and radiation. Letting the material derivative of $\theta$ in a parcel following the horizontal flow be denoted as $D_{h} \theta \equiv$ $(\partial \theta / \partial t+\mathbf{V} \cdot \nabla \theta)$, Eq. (3) implies

$$
w=\frac{F_{\theta}-D_{h} \theta}{\partial \theta / \partial z} \equiv \frac{F}{S}
$$

where $F$ is the total "forcing" and $S$ is the stratification. As before, let a double overbar denote the average over extreme events in both the control and warmer climates. According to Eq. (4), the changes $\delta w, \delta F$, and $\delta S$ between the control and warmer climates approximately satisfy

$$
\overline{\bar{w}}+\delta w / 2=\frac{\overline{\bar{F}}+\delta F / 2}{\overline{\bar{S}}+\delta S / 2},
$$

\footnotetext{
${ }^{3}$ For example, the composite mean $N_{m}^{2}$ over the location of the maximum precipitation in the control climate is $0.31 \times 10^{-4} \mathrm{~s}^{-2}$ in the south, exactly half the corresponding value of $N_{m}^{2}$ reported in Table 2.
} 
a) South

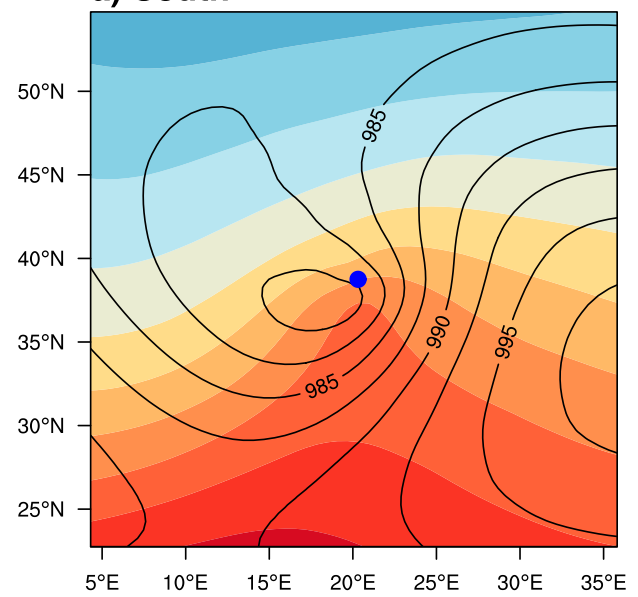

b) North

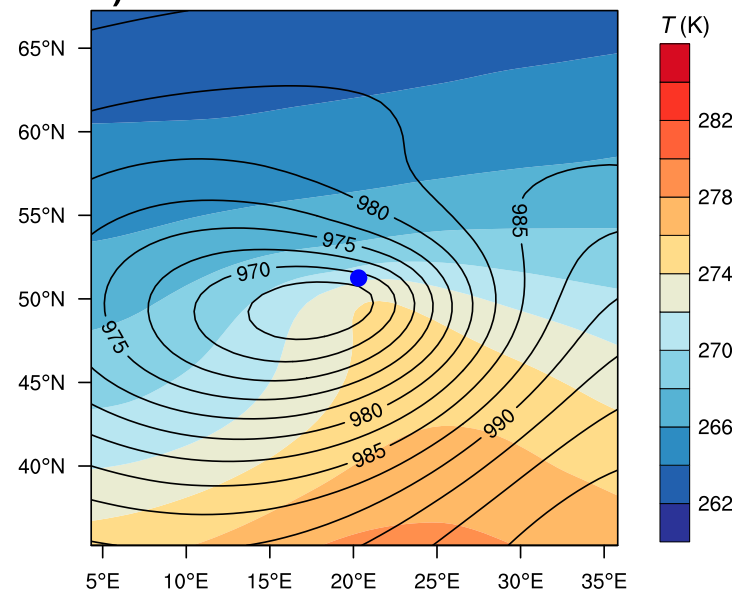

FIG. 7. Composite surface isobars $(\mathrm{hPa})$ and $850-\mathrm{hPa}$ temperatures $(\mathrm{K})$ for extreme precipitation events over the oceans. The location of the heavy precipitation event anchoring the composite is shown by the blue dot. The composited pressure (contours) and temperature (color shading) fields are the snapshots of those fields centered in time for each 6-h event. Data from the central latitude band in the (a) south (centered on $38.75^{\circ} \mathrm{N}$ ) and (b) north (centered on $51.25^{\circ} \mathrm{N}$ ). Those events within $15^{\circ}$ longitude to the west of mountains are omitted to avoid introducing mountaininduced perturbations.

which, without further approximation, implies ${ }^{4}$

$$
\frac{\delta w}{\overline{\bar{w}}}=\frac{\delta F / \overline{\bar{F}}-\delta S / \overline{\bar{S}}}{1+\delta S /(2 \overline{\bar{S}})} .
$$

Values of $w, F$, and $S$ were computed at the model level closest to $500 \mathrm{hPa}$ for all extreme events in the reference and doubled- $\mathrm{CO}_{2}$ climates. The terms in Eq. (3) were evaluated with the instantaneous model fields centered in time for each 6-h event. Spatial gradients were calculated with centered differences, and $\partial \theta / \partial t$ was approximated using the difference between $\theta 6 \mathrm{~h}$ after and before the central time for each event. Such a calculation cannot exactly balance the left and right sides of Eq. (3), because the HiRAM is a finite-volume model and calculates the terms in the thermodynamic equation using somewhat different formulae. In addition, our thermodynamic equation in Eq. (3) omits the contributions from both parameterized and numerical diffusion. However, the residual, by which the right side of Eq. (6) differs from $\delta w \overline{\bar{w}}$, is typically small.

These values of $w, F$, and $S$ were used to estimate the average of each term in Eq. (6) over the oceans and the plains in each latitude band. The results, expressed as sensitivities with respect to the global mean surface temperature, are plotted in Figs. 9a,b. Except in the two southernmost bands, the average sensitivity computed

\footnotetext{
${ }^{4}$ If $\delta S \ll \overline{\bar{S}}$, one could simplify the right side of Eq. (6) to $\delta F / \overline{\bar{F}}-\delta S / \overline{\bar{S}}$; however, in our case $\delta S$ is not small enough to be neglected.
}

from Eq. (6) (red dots) provides a good estimate of the average $\delta w / \overline{\bar{w}}$ evaluated directly from the vertical velocities output by the model (open circles). The errors in the south arise because the residual is larger in warmer regions, potentially related to the larger amounts of latent heat release in the corresponding extreme events. As shown by the vertical bars in Fig. $9, \delta F / \overline{\bar{F}}$ would produce an $11 \%-14 \% \mathrm{~K}^{-1}$ increase in $\delta w / \overline{\bar{w}}$, but this is partially offset by a $4 \%-7 \% \mathrm{~K}^{-1}$ increase in $\delta S / \overline{\bar{S}}$ arising from the stabilization of the dry atmosphere under global warming.

The sensitivity $\delta F \overline{\bar{F}}$ is almost entirely produced by changes in latent heating. To show this, the forcing $F$ may be separated into additive contributions from latent heat released by condensation $F_{l}$, adiabatic horizontal transport $-D_{h} \theta$, and a negligible contribution from radiative fluxes. The longitude-height distributions of the control-climate extreme-event averages $\bar{F}_{l}^{c}$ and $-\bar{D}_{h} \theta^{c}$, and their changes due to warming, are shown for the oceans and the plains in Fig. 10. The largest contribution to the total forcing in the control climate is from latent heating, while that from adiabatic transport is small, but not completely insignificant in the north. The changes (color fill) in the total forcing induced by warming are even more strongly dominated by the changes in latent heating. Note in particular, that the interval at which $\delta F_{l}$ is contoured in Figs. 10a,b is 10 times that used to contour $-\delta D_{h} \theta$ in Figs. $10 \mathrm{c}, \mathrm{d}$.

\section{Conclusions}

We have examined the global-warming-induced response of extreme midlatitude precipitation over idealized 
a) South

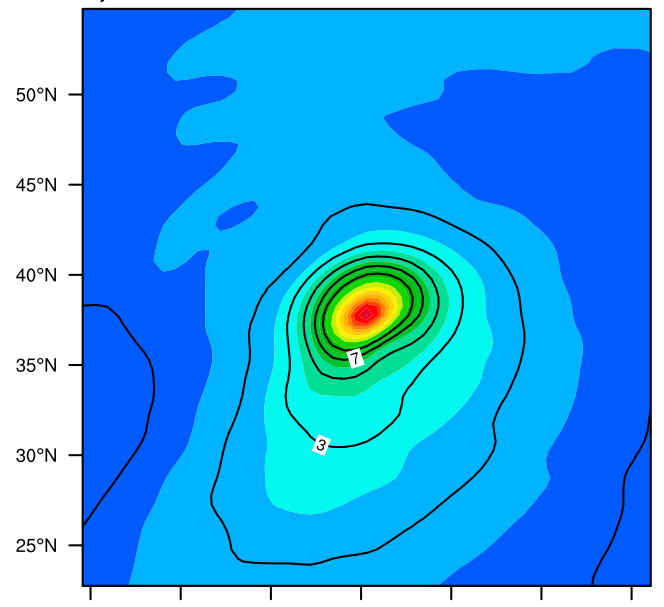

c)

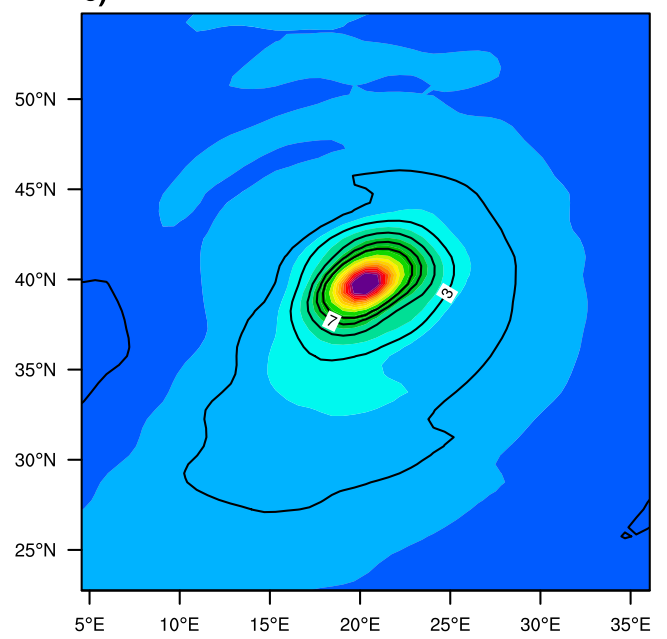

b) North

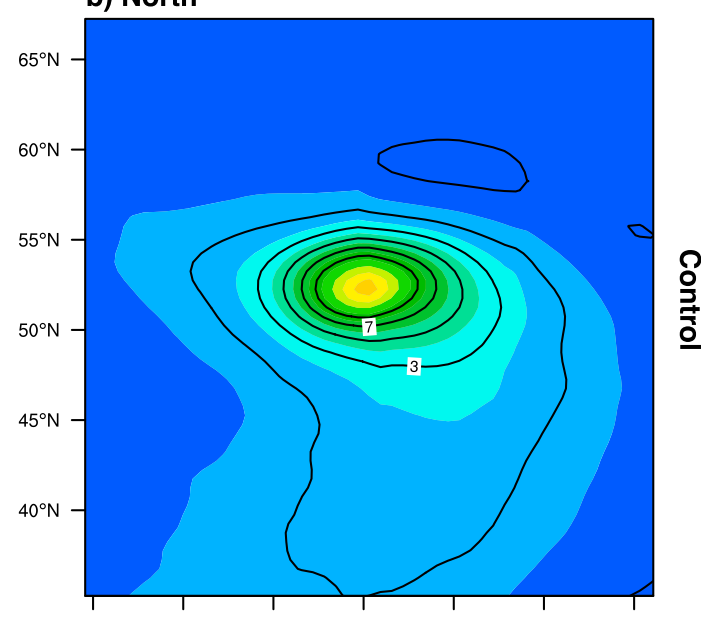

d)

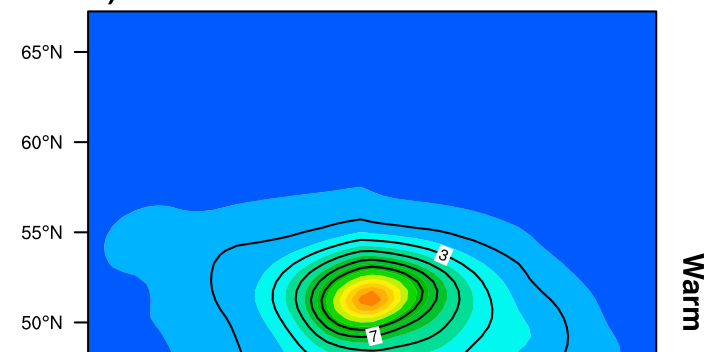

$\underset{3}{3}$

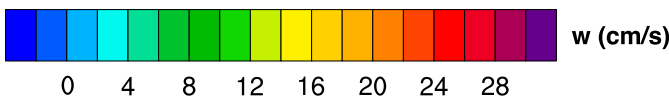

FIG. 8. Composite 500-hPa vertical velocity for heavy precipitation events over oceans, in the same latitude bands as those in Fig. 7. (a),(b) Events in the control simulation and (c),(d) events in the simulation with doubled $\mathrm{CO}_{2}$. Data over mountains are omitted to avoid mountain-induced perturbations in plots.

distributions of mountains, plains, and oceans very roughly representative of the North American continent. Extreme precipitation events were defined as those in which the 6-h precipitation in an approximately $50 \mathrm{~km}$ by $50 \mathrm{~km}$ grid cell exceeded the 99.9th percentile of all precipitation events in a $2.5^{\circ}$-wide latitude band over each type of underlying region. Comparing events in a control and a doubled $\mathrm{CO}_{2}$ simulation, the sensitivity of extreme precipitation over the plains and the oceans was similar, roughly $8 \%$ per degree of increase in the global-mean surface temperature. In contrast, the sensitivity of extreme precipitation over the mountains was only about $5 \% \mathrm{~K}^{-1}$. The thermodynamic contribution toward these sensitivities, because of the increase in the adiabatic lapse rate of saturation specific humidity in the warmer climate, does not contribute significantly to this difference; it was an almost uniform $6 \%$ $\mathrm{K}^{-1}$ over all three regions.

The difference between the mountains and the other regions arises from differences in the warming-induced response of vertical velocities during extreme events. Over the oceans and the plains, the strengthening of vertical velocities causes about $2 \% \mathrm{~K}^{-1}$ increases in the intensity of extreme precipitation as the currents of rising saturated air in midlatitude cyclones ascend more rapidly in the warmer climate. The regions of ascent also contract horizontally. The intensification and horizontal contraction of the updrafts in the warmer climate is accompanied by a decrease in the ratio of the moist to the 
TABLE 2. Fraction of the area in which grid-scale condensation is occurring at $500 \mathrm{hPa}\left(A_{s}\right)$, and the mean squared moist and dry Brunt-Väisälä frequency $\left(N_{m}^{2}\right.$ and $N^{2}$, respectively) at $500 \mathrm{hPa}$ in the saturated and the unsaturated portions of a box $50^{\circ}$ in latitude by $70^{\circ}$ in longitude centered at the point with maximum precipitation in the composites shown in Fig. 8.

\begin{tabular}{llccc}
\hline \hline & & $A_{s}$ & $N_{m}^{2}\left(10^{-4} \mathrm{~s}^{-2}\right)$ & $N^{2}\left(10^{-4} \mathrm{~s}^{-2}\right)$ \\
\hline \multirow{3}{*}{ North } & Control & $25 \%$ & 0.80 & 1.31 \\
& Warm & $21 \%$ & 0.70 & 1.38 \\
& Control & $18 \%$ & 0.68 & 1.24 \\
& Warm & $13 \%$ & 0.59 & 1.37 \\
\hline
\end{tabular}

dry static stability, consistent with previous theories of moist baroclinic instability (Emanuel et al. 1987).

In contrast, the vertical velocities during extreme events over the mountains are governed by mountain wave dynamics; the depth of the ascent is shallower than in the cyclones, and there is less global-warminginduced enhancement of that ascent, particularly in the lower troposphere where specific humidities are highest (see Fig. 5). The resulting dynamical contribution toward the sensitivity of the extreme precipitation ranges from $-2 \% \mathrm{~K}^{-1}$ in the south to $1 \% \mathrm{~K}^{-1}$ in the far north. A three-layer linear mountain-wave model, used to assess the factors responsible for the changes in the vertical velocities between the control and doubled- $\mathrm{CO}_{2}$ climates in the HiRAM simulations, suggests these changes arise primarily from an increase in uppertropospheric static stability and from changes in crossmountain wind speeds that would be consistent with a northward shift in the jet stream.
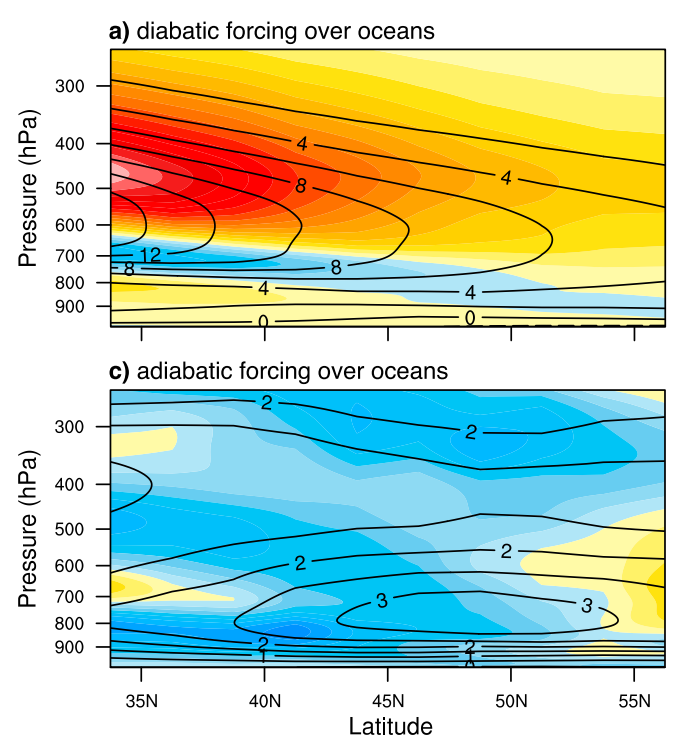
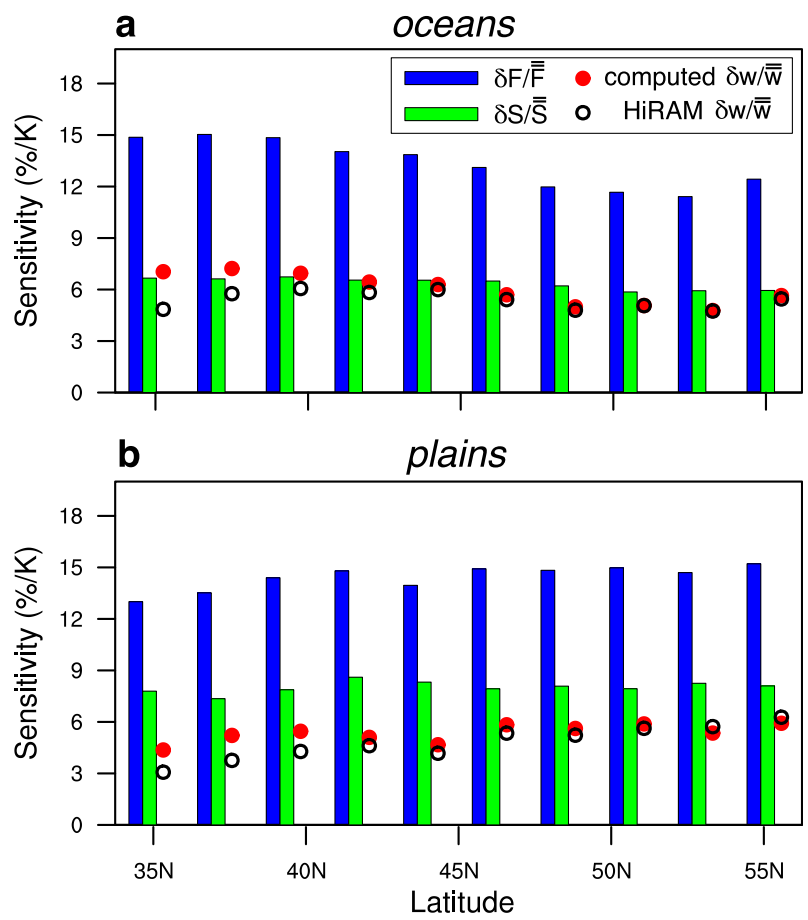

FIG. 9. The sensitivity at $500 \mathrm{hPa}$ of the total forcing $(\delta F / \overline{\bar{F}}$, blue bars), stratification $(\delta S / \overline{\bar{S}}$, green bars), vertical velocity $(\delta w / \overline{\bar{w}}$, red dots), and the vertical-velocity sensitivity computed from Eq. (6) (open circles) for extreme events over oceans and plains.

The simple idealized shapes of the mountains and continents used in our simulations preclude the direct quantitative application of our results to specific locations on the earth, yet the fundamental dynamical drivers
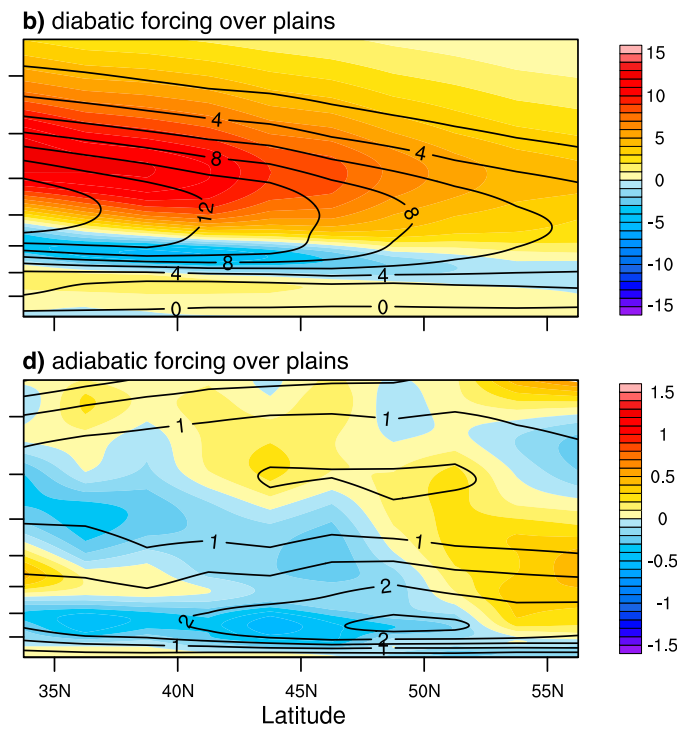

FIG. 10. Changes in (a),(b) diabatic forcing $\delta F_{l}$ and (c),(d) adiabatic forcing $-\delta D_{h} \theta$ (color fill), and the controlclimate extreme-event means (a),(b) $\bar{F}_{l}^{c}$ and (c),(d) $-\bar{D}_{h} \theta^{c}$ (contours), both in units of $10^{-4} \mathrm{~K} \mathrm{~s}^{-1}$. Note the color-fill scale for the changes in $\bar{F}_{l}^{c}$ is a factor of 10 larger than that for $-\bar{D}_{h} \theta^{c}$. 
of real-world midlatitude extremes are likely to be at least partially subject to the same basic sensitivities. The resolution of our data is also not adequate to assess the sensitivity of short-duration extreme events produced by warm-season convection (Lenderink and van Meijgaard 2008; Kendon et al. 2014). The response of midlatitude storms to warming is strongly dependent on model resolution (Willison et al. 2013, 2015). Thus reliable climatemodel projections of future extreme precipitation events would benefit from finer spatial resolutions to correctly capture both the decrease in the horizontal scale of regions of moist ascent in midlatitude cyclones and the changes in mountain-wave activity over topography.

Acknowledgments. The authors have benefited from conversations with Christopher Bretherton, and the comments of Penelope Maher and another anonymous reviewer. This research was supported by National Science Foundation (NSF) Grants AGS-1138977 and AGS1545927, and used the Extreme Science and Engineering Discovery Environment (XSEDE), which is supported by NSF Grant ACI-1053575.

\section{REFERENCES}

Allen, M., and W. Ingram, 2002: Constraints on future changes in climate and the hydrologic cycle. Nature, 419, 224-232, doi:10.1038/nature01092.

Attema, J. J., J. M. Loriaux, and G. Lenderink, 2014: Extreme precipitation response to climate perturbations in an atmospheric mesoscale model. Environ. Res. Lett., 9, 014003, doi:10.1088/1748-9326/9/1/014003.

Booth, J. F., S. Wang, and L. Polvani, 2013: Midlatitude storms in a moister world: Lessons from idealized baroclinic life cycle experiments. Climate Dyn., 41, 787-802, doi:10.1007/ s00382-012-1472-3.

Brayshaw, D. J., B. Hoskins, and M. Blackburn, 2009: The basic ingredients of the North Atlantic storm track. Part I: Land-sea contrast and orography. J. Atmos. Sci., 66, 2539-2558, doi:10.1175/2009JAS3078.1.

,-- , and,- 2011 : The basic ingredients of the North Atlantic storm track. Part II: Sea surface temperatures. J. Atmos. Sci., 68, 1784-1805, doi:10.1175/2011JAS3674.1.

Chang, S. W., R. J. Alliss, and S. Raman, 1993: SSM/I observations of ERICA IOP 4 marine cyclone: A comparison with in situ observations and model simulation. Mon. Wea. Rev., 121, 2452-2464, doi:10.1175/1520-0493(1993)121<2452:SOOEIM > 2.0.CO;2.

Diffenbaugh, N. S., J. S. Pal, R. J. Trapp, and F. Giorgi, 2005: Finescale processes regulate the response of extreme events to global climate change. Proc. Natl. Acad. Sci. USA, 102, 15774 15778 , doi:10.1073/pnas.0506042102.

Dominguez, F., E. Rivera, D. Lettenmaier, and C. Castro, 2012: Changes in winter precipitation extremes for the western United States under a warmer climate as simulated by regional climate models. Geophys. Res. Lett., 39, L05803, doi:10.1029/2011GL050762.

Emanuel, K. A., M. Fantini, and A. J. Thorpe, 1987: Baroclinic instability in an environment of small stability to slantwise moist convection. Part I: Two-dimensional models. J. Atmos.
Sci., 44, 1559-1573, doi:10.1175/1520-0469(1987)044<1559: BIIAEO $>2.0 . \mathrm{CO} ; 2$.

Emori, S., and S. J. Brown, 2005: Dynamic and thermodynamic changes in mean and extreme precipitation under changed climate. Geophys. Res. Lett., 32, L17706, doi:10.1029/ 2005GL023272.

Frierson, D. M. W., I. M. Held, and P. Zurita-Gotor, 2006: A grayradiation aquaplanet moist GCM. Part I: Static stability and eddy scale. J. Atmos. Sci., 63, 2548-2566, doi:10.1175/JAS3753.1.

Gochis, D., and Coauthors, 2015: The great Colorado flood of September 2013. Bull. Amer. Meteor. Soc., 96, 1461-1487, doi:10.1175/BAMS-D-13-00241.1.

Held, I. M., 2005: The gap between simulation and understanding in climate modeling. Bull. Amer. Meteor. Soc., 86, 1609-1614, doi:10.1175/BAMS-86-11-1609.

— global warming. J. Climate, 19, 5686-5699, doi:10.1175/JCLI3990.1.

Hsu, P.-C., T. Li, and H. Murakami, 2014: Moisture asymmetry and MJO eastward propagation in an aquaplanet general circulation model. J. Climate, 27, 8747-8760, doi:10.1175/JCLI-D-14-00148.1.

Kendon, E. J., N. M. Roberts, H. J. Fowler, M. J. Roberts, S. C. Chan, and C. A. Senior, 2014: Heavier summer downpours with climate change revealed by weather forecast resolution model. Nat. Climate Change, 4, 570-576, doi:10.1038/nclimate2258.

Kharin, V. V., F. W. Zwiers, X. Zhang, and G. C. Hegerl, 2007: Changes in temperature and precipitation extremes in the IPCC ensemble of global coupled model simulations. J. Climate, 20, 1419-1444, doi:10.1175/JCLI4066.1.

Kirshbaum, D. J., and D. R. Durran, 2004: Factors governing cellular convection in orographic precipitation. J. Atmos. Sci., 61, 682-698, doi:10.1175/1520-0469(2004)061<0682: FGCCIO $>2.0 . \mathrm{CO} ; 2$.

Klemp, J. B., and D. R. Lilly, 1975: The dynamics of wave-induced downslope winds. J. Atmos. Sci., 32, 320-339, doi:10.1175/ 1520-0469(1975)032<0320:TDOWID > 2.0.CO;2.

Lenderink, G., and E. van Meijgaard, 2008: Increase in hourly precipitation extremes beyond expectations from temperature changes. Nat. Geosci., 1, 511-514, doi:10.1038/ngeo262.

Maroon, E. A., D. M. W. Frierson, and D. S. Battisti, 2015: The tropical precipitation response to Andes topography and ocean heat fluxes in an aquaplanet model. J. Climate, 28, 381398, doi:10.1175/JCLI-D-14-00188.1.

Medeiros, B., B. Stevens, I. M. Held, M. Zhao, D. L. Williamson, J. G. Olson, and C. S. Bretherton, 2008: Aquaplanets, climate sensitivity, and low clouds. J. Climate, 21, 4974-4991, doi:10.1175/2008JCLI1995.1.

O'Gorman, P. A., 2012: Sensitivity of tropical precipitation extremes to climate change. Nat. Geosci., 5, 697-700, doi:10.1038/ngeo1568.

_ , and T. Schneider, 2009a: The physical basis for increases in precipitation extremes in simulations of 21st-century climate change. Proc. Natl. Acad. Sci. USA, 106, 14773-14777, doi:10.1073/pnas.0907610106.

$\longrightarrow$, and,$- 2009 \mathrm{~b}$ : Scaling of precipitation extremes over a wide range of climates simulated with an idealized GCM. J. Climate, 22, 5676-5685, doi:10.1175/2009JCLI2701.1.

Pall, P., T. Aina, D. A. Stone, P. A. Stott, T. Nozawa, A. G. Hilberts, D. Lohmann, and M. R. Allen, 2011: Anthropogenic greenhouse gas contribution to flood risk in England and Wales in autumn 2000. Nature, 470, 382-385, doi:10.1038/nature09762.

Pfahl, S., P. A. O'Gorman, and M. S. Singh, 2015: Extratropical cyclones in idealized simulations of changed climates. J. Climate, 28, 9373-9392, doi:10.1175/JCLI-D-14-00816.1. 
Ralph, F. M., P. J. Neiman, G. A. Wick, S. I. Gutman, M. D. Dettinger, D. R. Cayan, and A. B. White, 2006: Flooding on California's Russian River: Role of atmospheric rivers. Geophys. Res. Lett., 33, L13801, doi:10.1029/2006GL026689.

Rasmussen, K. L., and R. A. Houze, 2012: A flash-flooding storm at the steep edge of high terrain. Bull. Amer. Meteor. Soc., 93, 1713-1724, doi:10.1175/BAMS-D-11-00236.1.

Shi, X., and D. R. Durran, 2014: The response of orographic precipitation over idealized midlatitude mountains due to global increases in $\mathrm{CO}_{2}$. J. Climate, 27, 3938-3956, doi:10.1175/ JCLI-D-13-00460.1.

— , and D. Durran, 2015: Estimating the response of extreme precipitation over midlatitude mountains to global warming. J. Climate, 28, 4246-4262, doi:10.1175/JCLI-D-14-00750.1.

Siler, N., and D. Durran, 2015: Assessing the impact of the tropopause on mountain waves and orographic precipitation using linear theory and numerical simulations. J. Atmos. Sci., $\mathbf{7 2}$ 803-820, doi:10.1175/JAS-D-14-0200.1.

Stevens, B., and S. Bony, 2013: Climate change. What are climate models missing? Science, 340, 1053-1054, doi:10.1126/ science. 1237554 .
Takahashi, K., 2009: Radiative constraints on the hydrological cycle in an idealized radiative-convective equilibrium model. J. Atmos. Sci., 66, 77-91, doi:10.1175/2008JAS2797.1.

Vallis, G. K., P. Zurita-Gotor, C. Cairns, and J. Kidston, 2015: Response of the large-scale structure of the atmosphere to global warming. Quart. J. Roy. Meteor. Soc., 141, 1479-1501, doi:10.1002/qj.2456.

Voigt, A., and T. A. Shaw, 2015: Circulation response to warming shaped by radiative changes of clouds and water vapour. Nat. Geosci., 8, 102-106, doi:10.1038/ngeo2345.

Willison, J., W. A. Robinson, and G. M. Lackmann, 2013: The importance of resolving mesoscale latent heating in the North Atlantic storm track. J. Atmos. Sci., 70, 2234-2250, doi:10.1175/ JAS-D-12-0226.1.

, —, and,- 2015 : North Atlantic storm-track sensitivity to warming increases with model resolution. J. Climate, 28, 4513-4524, doi:10.1175/JCLI-D-14-00715.1.

Zhao, M., I. M. Held, S.-J. Lin, and G. A. Vecchi, 2009: Simulations of global hurricane climatology, interannual variability, and response to global warming using a $50-\mathrm{km}$ resolution GCM. J. Climate, 22, 6653-6678, doi:10.1175/ 2009JCLI3049.1. 